\title{
Basic Research on the Development of Skinny Jean Pants for Korean Women in Their $20 \mathrm{~s}^{+}$
}

\author{
Lee Minjeong · Sohn Heesoon \\ Lecturer, Dept, of Clothing and Textiles, Sookmyung Women's University \\ Prof.,, Dept, of Clothing and Textiles, Sookmyung Women's University
}

\begin{abstract}
This study is meaningful in that it builds the basic data necessary for developing skinny jeans for Korean women in their 20s based on the level of satisfaction with the apparel fit by body parts and brand choices gathered from studies on the skinny jeans consumption pattern among students in their 20s and on the results of the movement functionality and appearance sensory tests conducted on skinny jeans from six labels with the highest market share, popularity, and brand recognition, with the goal of developing skinny jeans for Korean women in their 20s.
\end{abstract}

Key Words : Denim pants, Fit, Jeans, Skinny jean pants, Women's fashion.

\section{Introduction}

Jeans, which started as work clothes for miners upon the start of the Gold Rush back in 1848, thanks to their practicality, have been loved by the public for over 150 years as a major clothing item that leads the fashion trends today. The recent changes in lifestyle thanks to the spread of the five-workday week have helped power casual styling in the country, which has in turn led to an increased demand for and to the development of jeans.
The casual clothing market was worth 10.7 billion won in 2011, accounting for $34.9 \%$ of South Korea's total clothing market worth 29.205 trillion won, of which the jeans market accounts for $6.7 \%^{1)}$. In addition, since the 1990 s, jeans have been leading fashion trends, with the variety of silhouettes and styles by domestic and foreign labels and by foreign brands like Levi's, Guess Jeans, and Calvin Klein Jeans as the frontrunners. In terms of market share, Guess Jeans $>$ Calvin Klein Jeans $>$ Buckaroo Jeans $>$ Levi's were the top names in the order of ranking,

\footnotetext{
${ }^{+}$This study was sponsored by 2011 SookMyung Women's University's school research fund.

Corresponding author: Sohn Heesoon, Tel.+82-2-710-9461, Fax.+82-2-710-9461

E-mail: pattern@sm.ac.kr
} 
Lee Minjeong - Sohn Heesoon / Basic Research on the Development of Skinny Jean Pants for

according to the jeans sales at the major department stores in South Korea from January to November 20112). Recently, foreign premium brands like True Religion Jeans, Diesel Jeans, Robin's Jeans, and Nudie Jeans have entered the market, with a strong presence ${ }^{3)}$.

Meanwhile, skinny jeans are gaining in popularity among the young female population on the back of the preference for slimmer and sexier body lines stemming from the continued weight loss fever ${ }^{4}$.

Related academic studies are also under way as jeans are now a major fashion item. The precedent studies on jeans were heavily focused on styling habits and $\mathrm{fit}^{(5) 67) 8 \text { ) }}$, analysis style and design $^{910)}$, and pattern development ${ }^{11)^{12133}}$ and research consumers ${ }^{14) 15)}$. However, the studies on the development of skinny jeans, which have become an important styling element, are insufficient at this point, although they are in demand.

Therefore, this study, in a joint research effort with Basic House Corporation, would like to establish basic data materials for the development of skinny jeans aimed for Korean women in their 20s by finding out the consumers' preference by looking into their styling attitudes, such as their brand recognition, preferences, and preferred styling and fitting, and by analyzing, through comparison and contrast, the skinny jeans from six major brands by market share.

\section{Method}

\section{Research Consumer}

In a precedent research ${ }^{16)}$, a survey was conducted on consumers' tendencies based on the jeans-wearing habits of female students in their 20s. The leading research surveyed 30 students at Sookmyung Women's University on June 1 7, 2011. In the present study, a survey was conducted on June 13 30, 2011 among 313 female students aged 18 to 25 who were residing in Seoul and Gyeonggi Province. The survey questionnaire consisted of 21 questions: three on demographics and 18 on styling attitudes like jeans brand recognition, preference, and style and fitting preferences. A total of 21 jeans brands, selected by studying the jeans brands in department stores and street shops, were used in the survey. The questionnaire was in a multiple-response format, with each question worth 5 points in a Likert scale. SPSS 12.0 was used for frequency statistics, and descriptive statistics was used to analyze the results.

\section{Comparison of skinny jeans products and fit}

A total of six brands-GUESS, CK JEANS, BUCKAROO, LEVI'S, GIORDANO and UNIQLOwere selected based on the results of a South Korean market analysis and on MDrecommended data from Basic House Corporation. $\langle$ Tab. 1 $\rangle$. The products that were used for comparison purposes were the skinny jeans models with the best sales from each brand. The size of the products from each brand that was used in this analysis was close to the waist-hip ratio of 66 to 90 centimeters. <Fig. 1> shows dressed in model of the brands' skinny jeans products.

Next, evaluation of movements and sensory evaluation of appearance were conducted based on the results of the precedent research ${ }^{17)}$, to compare the brands' skinny jeans of the fit. The evaluation of movements six items suggested in $\langle$ Tab. 2> according to body parts by making a 
subject walk at a moderate pace, bend over by $90^{\circ}$, sit up straight on the chair by $90^{\circ}$, walk up the stairs, squat, and sit cross-legged while wearing each brand's skinny jeans product <Fig. 2>. In addition, while all six movements were carried out simultaneously for five minutes, and the fit satisfaction on the six body parts was evaluated $\langle T a b .2\rangle$. The subjects' six different movements were evaluated according to different body parts, and the inspectors evaluated 13 items on the front, 4 items on the side, and 11 items on the back, total 28items <Tab. 3> based on a 5-point Likert scale. The inspection group was made of six clothing pattern makers and graduate students majoring in clothing pattern construction. The subjects were three people who had the closest body sizes to type
3 (the average body size for women in their 20s) selected from 150 female students aged 19 to 24 residing in Seoul in 2011 ${ }^{18)}$, based on data comparing their 2010(Size Korea) ${ }^{19}$ body sizes and their 2011 ones, as suggested in $\langle$ Tab. $4>$.

\section{Results}

\section{Analysis of jeans wearing attitude}

1) Demographic characteristics of the surveyed participants

This study tested college students aged 18 to 25 residing in Seoul and Gyeonggi Province among the female jeans consumers in their 20s.

<Tab. 1> Skinny jean pants of brands

\begin{tabular}{c|c|c|c|c|c|c}
\hline \hline Brand & GUESS & CK JEANS & BUCKAROO & LEVI'S & GIORDANO & UNIQLO \\
\hline $\begin{array}{c}\text { Size } \\
(\mathrm{cm})\end{array}$ & $64-90$ & $64-90$ & $66-90$ & $66-91$ & $66-79$ & 66 \\
\hline $\begin{array}{c}\text { Fabric } \\
(\%)\end{array}$ & $\begin{array}{c}\text { Cotton 58 } \\
\text { Polyester 2 }\end{array}$ & $\begin{array}{c}\text { Cotton 98 } \\
\text { Polyurethane 2 }\end{array}$ & $\begin{array}{c}\text { Cotton 69 } \\
\text { Polyester 29 } \\
\text { Polyurethane 2 }\end{array}$ & $\begin{array}{c}\text { Cotton 98 } \\
\text { Polyurethane 2 }\end{array}$ & $\begin{array}{c}\text { Cotton 72 } \\
\text { Polyester 28 }\end{array}$ & $\begin{array}{c}\text { Cotton 68 } \\
\text { Polyester 32 }\end{array}$ \\
\hline \hline
\end{tabular}

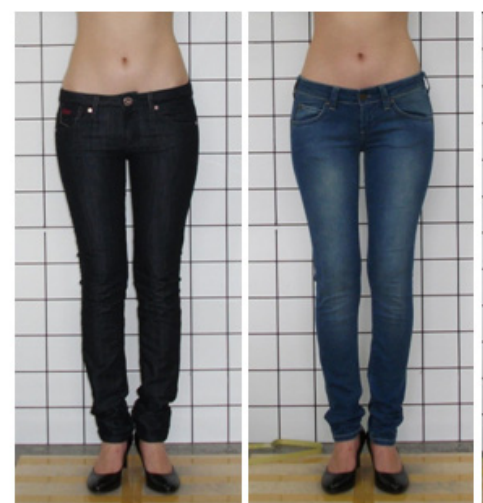

GUESS

CKJEANS
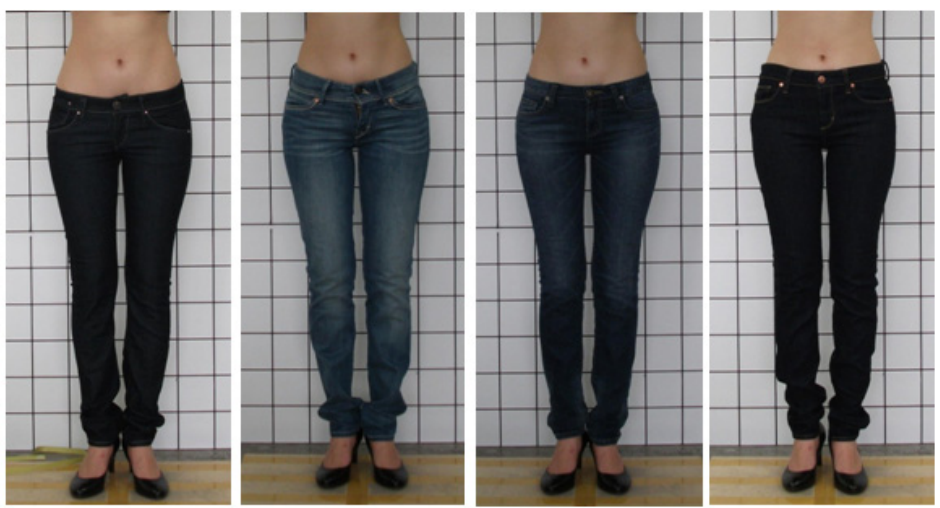

BUCKAROO
LEVI'S

GIORDANO

<Fig. 1> Skinny jeans style and fitting patterns by brands 
Lee Minjeong - Sohn Heesoon / Basic Research on the Development of Skinny Jean Pants for

\begin{tabular}{|c|c|c|c|}
\hline \multicolumn{2}{|c|}{$\begin{array}{l}\text { Evaluated } \\
\text { parts }\end{array}$} & \multicolumn{2}{|r|}{ Evaluations items } \\
\hline \multirow{13}{*}{$\begin{array}{l}F \\
r \\
o \\
n \\
t\end{array}$} & \multirow{3}{*}{ Waist } & 1 & $\begin{array}{l}\text { Is the level of the waist circumstance line } \\
\text { proper? }\end{array}$ \\
\hline & & 2 & $\begin{array}{l}\text { Is there enough extra room for the waist } \\
\text { area? }\end{array}$ \\
\hline & & 3 & $\begin{array}{l}\text { Is there any wrinkling or tightening at the } \\
\text { waistline? }\end{array}$ \\
\hline & \multirow{2}{*}{ Hip } & 4 & $\begin{array}{l}\text { Is there enough extra room at the hip } \\
\text { area? }\end{array}$ \\
\hline & & 5 & $\begin{array}{l}\text { Is there any wrinkling or tightening at the } \\
\text { hip area? }\end{array}$ \\
\hline & \multirow[b]{2}{*}{ Crotch } & 6 & Is there enough room near the crotch? \\
\hline & & 7 & $\begin{array}{l}\text { Is there any wrinkling or tightening near the } \\
\text { crotch? }\end{array}$ \\
\hline & \multirow[b]{2}{*}{ Thigh } & 8 & Is there enough room near the thighs? \\
\hline & & 9 & $\begin{array}{l}\text { Is there any wrinkling or tightening near the } \\
\text { thighs? }\end{array}$ \\
\hline & Knee & 10 & Is there enough extra room near the knees? \\
\hline & \multirow{2}{*}{$\begin{array}{c}\text { Hemline } \\
\mathrm{s}\end{array}$} & 11 & Is the hemlines level proper? \\
\hline & & 12 & \begin{tabular}{|llll}
$\begin{array}{l}\text { Is there enough extra room near the } \\
\text { hemlines? }\end{array}$ & & & \\
\end{tabular} \\
\hline & Total & 13 & Does it look nice on the outside? \\
\hline \multirow{4}{*}{$\begin{array}{l}\mathrm{S} \\
\mathrm{i} \\
\mathrm{d} \\
\mathrm{e} \\
\mathrm{s}\end{array}$} & $\begin{array}{l}\text { Side } \\
\text { seam }\end{array}$ & 14 & Is the positioning of the side seam proper? \\
\hline & \multirow{2}{*}{ Waist } & 15 & $\begin{array}{l}\text { Is the steepness of the waist circumference } \\
\text { line proper? }\end{array}$ \\
\hline & & 16 & $\begin{array}{l}\text { Is there enough extra room at the } \\
\text { waistline? }\end{array}$ \\
\hline & Total & 17 & Is the overall appearance nice? \\
\hline \multirow{11}{*}{$\begin{array}{l}\mathrm{B} \\
\mathrm{a} \\
\mathrm{c} \\
\mathrm{k}\end{array}$} & \multirow{3}{*}{ Waist } & 18 & $\begin{array}{l}\text { Is the level of the waist circumference line } \\
\text { proper? }\end{array}$ \\
\hline & & 19 & $\begin{array}{l}\text { Is there enough extra room near the } \\
\text { waistline? }\end{array}$ \\
\hline & & 20 & $\begin{array}{l}\text { Is there any wrinkling or tightening near the } \\
\text { waistline? }\end{array}$ \\
\hline & Yoke & 21 & Does the yoke look nice on the outside? \\
\hline & \multirow{2}{*}{ Hip } & 22 & $\begin{array}{l}\text { Is there enough extra room near the hip } \\
\text { area? }\end{array}$ \\
\hline & & 23 & $\begin{array}{l}\text { Is there any wrinkling or tightening near the } \\
\text { hip area? }\end{array}$ \\
\hline & \multirow[b]{2}{*}{ Crotch } & 24 & Is there enough room near the crotch? \\
\hline & & 25 & $\begin{array}{l}\text { Is there any wrinkling or tightening at the } \\
\text { crotch? }\end{array}$ \\
\hline & \multirow{2}{*}{ Thigh } & 26 & $\begin{array}{l}\text { Is there enough extra room near the } \\
\text { thighs? }\end{array}$ \\
\hline & & 27 & $\begin{array}{l}\text { Is there any wrinkling or tightening near the } \\
\text { thighs? }\end{array}$ \\
\hline & Total & 28 & Does it look nice on the outside? \\
\hline
\end{tabular}

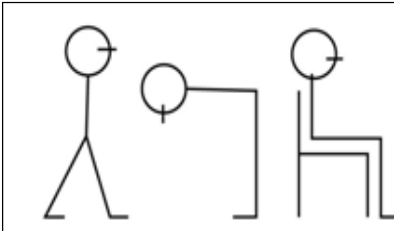

$\langle$ Mov, 1〉〈Mov, 2〉〈Mov, 3〉

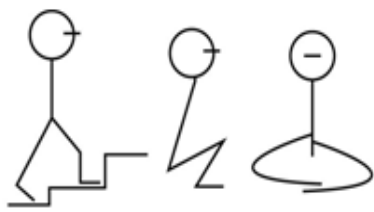

$\langle$ Mov, 4〉 〈Mov, 5〉 〈Mov, 6〉

Movement 1: Walk at a moderate pace $(50-60 \mathrm{~cm})$.

Movement 2: Bend over by $90^{\circ}$.

Movement 3: Sit up straight on a chair by $90^{\circ}$

Movement 4: Walk up a stair.

Movement 5: Squat.

Movement 6: Sit down cross-legged.

<Fig. 2> evaluation of movements

<Tab. 2> Evaluation items of the movement for jeans

\begin{tabular}{c|l}
\hline \hline \multicolumn{2}{c}{ Item } \\
\hline 1 & $\begin{array}{l}\text { Is comfortable near the } \\
\text { waistline? }\end{array}$ \\
\hline 2 & $\begin{array}{l}\text { Is comfortable near the } \\
\text { belly? }\end{array}$ \\
\hline 3 & $\begin{array}{l}\text { Is comfortable near the } \\
\text { hips? }\end{array}$ \\
\hline 4 & $\begin{array}{l}\text { Is comfortable near the } \\
\text { thighs? }\end{array}$ \\
\hline 5 & $\begin{array}{l}\text { Is comfortable at the } \\
\text { crotch? }\end{array}$ \\
\hline 6 & $\begin{array}{l}\text { Is Comfortable near the } \\
\text { knees? }\end{array}$ \\
\hline \hline
\end{tabular}


$<$ Tab. 4> 2011 result-subject of comparison with the 6th Korean's Human body size on measurement data

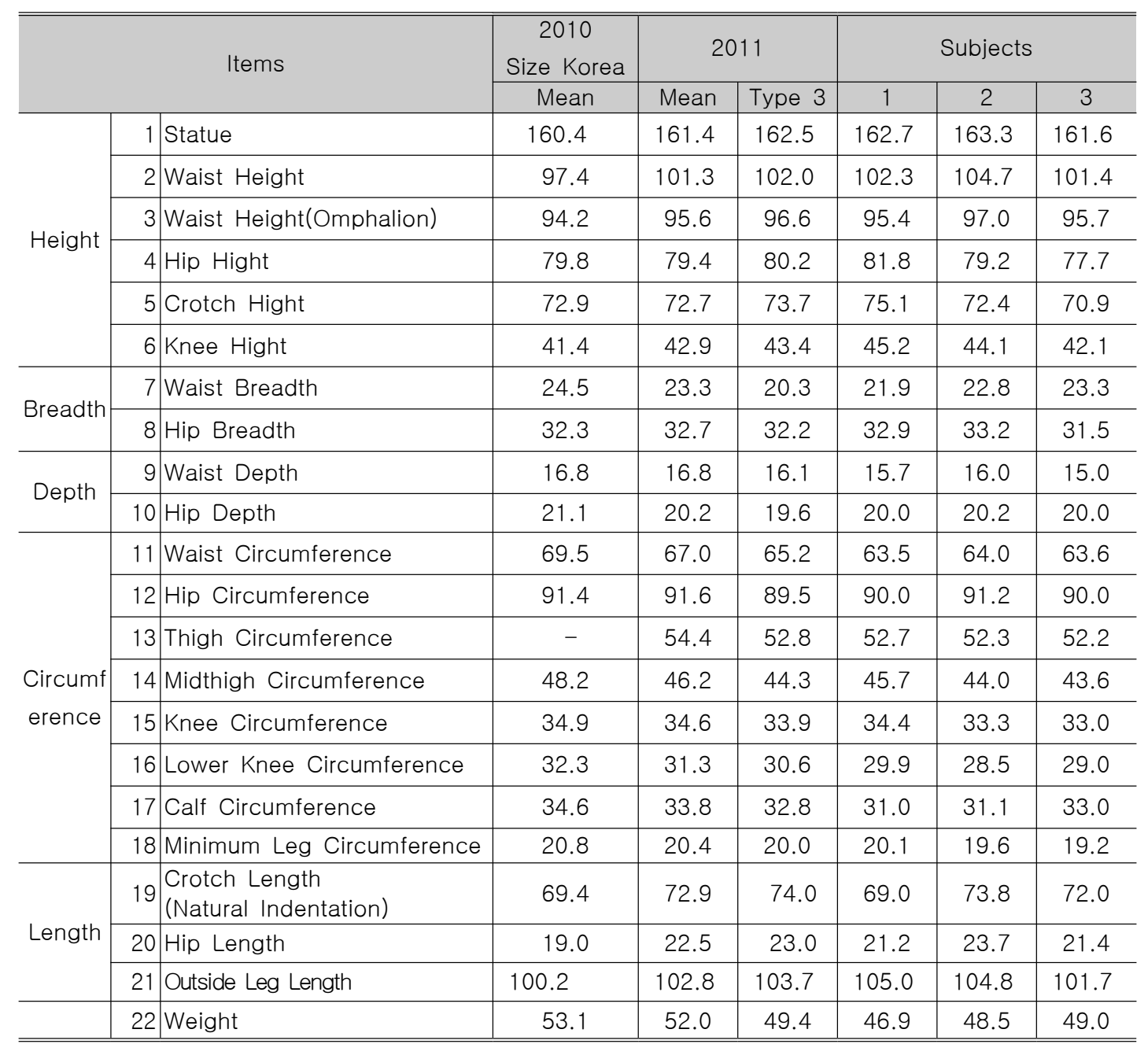

The demographic characteristics of the evaluated participants are as shown in the following <Tab. $5>$. By age, the percentage of those in their 20s was the highest (27.2\%), and those in the early 20s comprised the majority, with the 21-year -olds accounting for $18.9 \%$. Fashion majors made up $53.4 \%$ of the study subjects, and most of them showed sensitivity to fashion trends. $27.5 \%$ of them were earning 300,000 to 390,000 won a month, and $19.2 \%$ were earning less than 100,000 won a month. Also, 42.2\% would normally spend 50,000 to 99,000 won for a pair of jeans, meaning they usually consume moderately priced products $\langle T a b .6\rangle$. 
Lee Minjeong · Sohn Heesoon / Basic Research on the Development of Skinny Jean Pants for Korean Women in Their 20s

$<$ Tab. 5> Demographic characteristics of the survey participants

\begin{tabular}{|c|c|c|c|}
\hline Factor & Classification & Frequency & $(\%)$ \\
\hline \multirow{9}{*}{ Age } & 18 & 2 & 0.6 \\
\hline & 19 & 2 & 0.6 \\
\hline & 20 & 85 & 27.2 \\
\hline & 21 & 59 & 18.9 \\
\hline & 22 & 40 & 12.8 \\
\hline & 23 & 52 & 16.6 \\
\hline & 24 & 50 & 16.0 \\
\hline & 25 & 23 & 7.3 \\
\hline & Total & 313 & 100.0 \\
\hline \multirow{3}{*}{ College Major } & Fashion & 167 & 53.4 \\
\hline & Non-fashion & 146 & 46.6 \\
\hline & Total & 313 & 100.0 \\
\hline \multirow{7}{*}{$\begin{array}{l}\text { Average Monthly } \\
\text { Income }(W)\end{array}$} & Less than 100.000 & 60 & 19.17 \\
\hline & $100.000 \sim 200.000$ & 17 & 5.43 \\
\hline & $200.000 \sim 290.000$ & 58 & 18.53 \\
\hline & $300.000 \sim 390.000$ & 86 & 27.48 \\
\hline & $400.000 \sim 490.000$ & 50 & 15.97 \\
\hline & More than 500.000 & 42 & 13.42 \\
\hline & Total & 313 & 100.00 \\
\hline
\end{tabular}

$\langle$ Tab. 6> Normally spend the price for a pair of jeans

\begin{tabular}{c|c|c}
\hline \hline Price $(W)$ & Frequency(N) & $(\%)$ \\
\hline Less than 50.000 & 75 & 23.96 \\
\hline $50.000 \sim 99.000$ & 132 & 42.17 \\
\hline $100.000 \sim 149.000$ & 71 & 22.68 \\
\hline $150.000 \sim 199.000$ & 20 & 6.39 \\
\hline $200.000 \sim 249.000$ & 4 & 1.28 \\
\hline $250.000 \sim 299.000$ & 4 & 1.28 \\
\hline More than 300.000 & 7 & 2.24 \\
\hline Total & 313 & 100.0 \\
\hline \hline
\end{tabular}

2) Analysis of jeans brand recognition and preference

A total of 12 brands, namely CK Jeans, Levi's,
Guess, Polo Jeans, DKNY, GAP, UNIQLO, Giordano, BASIC HOUSE, BANG BANG, H\&M, and TBJ, had a $5 \%$ or higher rate of response in the research of jeans brand recognition. 
Premium jeans brands came in at the bottom of the brand recognition ranking, with a $1.4 \%$ response. Levi's (6.9\%), GUESS (6.7\%), CK Jeans (6.6\%), BANG BANG (6.4\%), and POLO JEANS (6.0\%) had the highest levels of brand recognition response. Second-tier brands with low pricing strategies like BANG BANG (6.4\%), BASIC HOUSE (5.9\%), and UNIQLO (5.9\%) had a $5 \%$ brand recognition rate $\langle$ Tab. 7$\rangle$.
In terms of preference $\langle T a b .8\rangle$, the jeans from CK Jeans, Levi's, Guess, GAP, and UNIQLO, and from smaller brands that distribute to smaller shops in Dongdeamoon Markets, gained $5 \%$ or more responses. CK Jeans topped the list (15.1\%) among the 21 brands, and Levi's (14.8\%), GUESS (14.3\%), and UNIQLO (9.0\%), and smaller brands in Dongdeamoon Markets $(5.8 \%)$ followed. In the middle of the

$\langle$ Tab. 7> Jeans brand recognition level

$(N=313)$

\begin{tabular}{|c|c|c|}
\hline Brand & Frequency(N) & (\%) \\
\hline CK & 284 & $6.6 \%$ \\
\hline Levi's & 296 & $6.9 \%$ \\
\hline Guess & 289 & $6.7 \%$ \\
\hline BUCKAROO & 192 & $4.5 \%$ \\
\hline Disel & 202 & $4.7 \%$ \\
\hline EVISU & 192 & $4.5 \%$ \\
\hline POLO JEAN & 256 & $6.0 \%$ \\
\hline DKNY & 228 & $5.3 \%$ \\
\hline TANKUS & 92 & $2.1 \%$ \\
\hline GAP & 252 & $5.9 \%$ \\
\hline Giordano & 242 & $5.6 \%$ \\
\hline SHANE JEAN & 114 & $2.7 \%$ \\
\hline UNIQLO & 255 & $5.9 \%$ \\
\hline$H \& M$ & 247 & $5.8 \%$ \\
\hline BASIC HOUSE & 255 & $5.9 \%$ \\
\hline FRJ & 166 & $3.9 \%$ \\
\hline BANG BANG & 272 & $6.4 \%$ \\
\hline TBJ & 236 & $5.5 \%$ \\
\hline Premium Jean & 58 & $1.4 \%$ \\
\hline Dongdeamoon Market & 136 & $3.2 \%$ \\
\hline Others & 22 & $0.5 \%$ \\
\hline Total & 4286 & $100.0 \%$ \\
\hline
\end{tabular}

※ Multiple responses allowed 
Lee Minjeong - Sohn Heesoon / Basic Research on the Development of Skinny Jean Pants for Korean Women in Their 20s

ranking were Diesel, H\&M, POLO JEANS, and GIORDANO. At the bottom of the list were SHANE JEANS, EVISU, FRJ, and TANKUS. In terms of brand preference, Levi's (6.9\%), GUESS (6.7\%) and CK Jeans (6.6\%) garnered slightly different positions in a simple preference ranking. The three brands, however, were still the top three brands among the 21 brands. There were brands like UNIQLO or the smaller brands that distribute to marketplaces that have significantly gained popularity relative to their brand recognition level. This helps in understanding that there are factors to be considered when making a skinny jeans purchase, such as one's average monthly income.

3) Preferred style of jeans

College students showed preference for skinny jeans $(50.7 \%)$, shorts (17.5\%), and slim straight style $(14.9 \%)<T a b .9\rangle$. The outstandingly high preference for skinny jeans over other styles of pants indicates that the skin-tight jeans style is the most preferred style of jeans among college students these days.

4) Fit of jeans

As $\langle$ Tab. 10 $\rangle$ indicates, female college students

$\langle$ Tab. 8> Jeans brand preference level

$(N=313)$

\begin{tabular}{c|c|c}
\hline \hline Brand & Frequency(N) & $(\%)$ \\
\hline CK & 162 & $15.1 \%$ \\
\hline Levi's & 159 & $14.8 \%$ \\
\hline Guess & 153 & $14.3 \%$ \\
\hline BUCKAROO & 31 & $2.9 \%$ \\
\hline Disel & 50 & $4.7 \%$ \\
\hline EVISU & 12 & $1.1 \%$ \\
\hline POLO JEAN & 38 & $3.5 \%$ \\
\hline DKNY & 22 & $2.1 \%$ \\
\hline TANKUS & 3 & $0.3 \%$ \\
\hline GAP & 54 & $5.0 \%$ \\
\hline Giordano & 42 & $3.9 \%$ \\
\hline SHANE JEAN & 16 & $1.5 \%$ \\
\hline UNIQLO & 97 & $9.0 \%$ \\
\hline H\&M & 49 & $4.6 \%$ \\
\hline BASIC HOUSE & 19 & $1.8 \%$ \\
\hline FRJ & 11 & $1.0 \%$ \\
\hline BANG BANG & 30 & $2.8 \%$ \\
\hline TBJ & 25 & $2.3 \%$ \\
\hline Premium Jean & 24 & $2.2 \%$ \\
\hline Dongdeamoon Market & 61 & $5.8 \%$ \\
\hline Others & 14 & $1.3 \%$ \\
\hline Total & & $100.0 \%$ \\
\hline responses & 1072 & \\
\hline Mal & & \\
\hline
\end{tabular}

* Multiple responses allowed 
have different levels of satisfaction with the comfort and fit of their jeans, scoring 3.73 points on average. By body part, some survey participants expressed dissatisfaction at their knee (3.35) and crotch (3.37) areas. In addition, the distribution chart of level of satisfaction with fitting in 〈Tab. 11> shows an even distribution of answers like "moderate" and "yes," indicating that most female college students who are skinny jeans consumers are satisfied with the jeans' comfortable fit.

As for complaints over skinny jeans, some commented on their discomfort with the fit in their waist, hip born, hip, and thigh areas. That is, when donning a pair of skinny jeans, focusing on these areas, the pair does not fit properly in some body parts. In particular, there was a notable dissatisfaction with the fact that most jeans now have a much shorter crotch length. The subjects explained their complaints, saying that they need to be cautious about their back when sitting down in the pants as they do not want their underwear to show, and that they do not feel that the pair of jeans complements their body as it makes their legs look shorter.

\section{Analysis of the fit of skinny jeans}

The results are as follows.

$\langle$ Tab. 9> Preferred style of jeans

$(\mathrm{N}=313)$

\begin{tabular}{c|c|c}
\hline \hline Jeans Style & Frequency(N) & $(\%)$ \\
\hline Skinny & 249 & $50.7 \%$ \\
\hline Boots-cut & 19 & $3.9 \%$ \\
\hline Shorts & 86 & $17.5 \%$ \\
\hline Straight & 48 & $9.8 \%$ \\
\hline Slim Straight & 73 & $14.9 \%$ \\
\hline Baggy & 16 & $3.3 \%$ \\
\hline Total & 491 & $100.0 \%$ \\
\hline \hline
\end{tabular}

※ Multiple responses allowed

$\langle$ Tab. 10 $>$ Satisfaction with fit of jeans

$(N=313)$

\begin{tabular}{c|c|c}
\hline \hline Parts & Mean & MD \\
\hline Total & 3.73 & 0.85 \\
\hline Waist & 3.51 & 0.84 \\
\hline Abdominal Region & 3.44 & 0.82 \\
\hline Hip & 3.47 & 0.82 \\
\hline Thigh & 3.41 & 0.88 \\
\hline Crotch & 3.37 & 0.78 \\
\hline Knee & 3.35 & 0.82 \\
\hline \hline
\end{tabular}


Lee Minjeong · Sohn Heesoon / Basic Research on the Development of Skinny Jean Pants for

$<$ Tab. 11> Distribution chart of Satisfaction with fit of jeans

\begin{tabular}{|c|c|c|c|c|c|c|c|c|c|c|c|c|c|c|}
\hline \multirow{2}{*}{$\begin{array}{c}\text { Fitting } \\
\text { Satisfaction }\end{array}$} & \multicolumn{2}{|c|}{ Total } & \multicolumn{2}{|c|}{ Waist } & \multicolumn{2}{|c|}{$\begin{array}{c}\text { Abdominal } \\
\text { Region }\end{array}$} & \multicolumn{2}{|c|}{ Hip } & \multicolumn{2}{|c|}{ Thigh } & \multicolumn{2}{|c|}{ Crotch } & \multicolumn{2}{|c|}{ Knee } \\
\hline & $\begin{array}{l}\text { Fre. } \\
(\mathrm{N})\end{array}$ & $(\%)$ & $\begin{array}{l}\text { Fre. } \\
(\mathrm{N})\end{array}$ & $(\%)$ & $\begin{array}{l}\text { Fre. } \\
(\mathrm{N})\end{array}$ & $(\%)$ & $\begin{array}{l}\text { Fre. } \\
(\mathrm{N})\end{array}$ & (\%) & $\begin{array}{l}\text { Fre. } \\
(\mathrm{N})\end{array}$ & $(\%)$ & $\begin{array}{l}\text { Fre. } \\
(\mathrm{N})\end{array}$ & $(\%)$ & $\begin{array}{l}\text { Fre. } \\
(\mathrm{N})\end{array}$ & $(\%)$ \\
\hline Absolutely not & 3 & 1.0 & 6 & 1.9 & 2 & 0.6 & 2 & 0.6 & 4 & 1.3 & 8 & 2.6 & 6 & 1.9 \\
\hline Not & 16 & 5.1 & 24 & 7.7 & 30 & 9.6 & 38 & 12.1 & 30 & 9.6 & 34 & 10.9 & 32 & 10.2 \\
\hline Moderate & 100 & 31.9 & 118 & 37.7 & 150 & 47.9 & 115 & 36.8 & 118 & 37.7 & 118 & 37.7 & 143 & 45.7 \\
\hline Yes & 136 & 43.5 & 135 & 43.1 & 111 & 35.5 & 136 & 43.5 & 138 & 44.1 & 129 & 41.2 & 112 & 35.8 \\
\hline Absolutely yes & 58 & 18.5 & 30 & 9.6 & 20 & 6.4 & 22 & 7.0 & 23 & 7.3 & 24 & 7.7 & 20 & 6.4 \\
\hline Total & 313 & 100 & 313 & 100 & 313 & 100 & 313 & 100 & 313 & 100 & 313 & 100 & 313 & 100 \\
\hline
\end{tabular}

※ Fre. : Frequency

\section{1) Evaluation of movements}

The subjects were advised to wear a pair of skinny jeans and to evaluate its comfort on each body part (waist, belly, hips, thighs, crotch, and knees) after walking at a moderate pace, bending over by $90^{\circ}$, sitting up straight on a chair by $90^{\circ}$, walking up the stairs, squatting, and sitting cross-legged, and the results are shown in $\langle$ Tab. 12〉 in their mean values. CK Jeans showed the highest level of satisfaction, with 4.5 or higher scores in 15 areas. Next was UNIQLO, with 4.5 points or higher in 9 areas. Both brands showed a high level of satisfaction in the waist and belly areas. Although the evaluation results showed high satisfaction levels (3.5 points) at these two areas, the subjects expressed discomfort in areas like the knees, thighs, crotch, and hips.

In the comprehensive total evaluation of movements on the six body parts, CK JEANS (4.5) > UNIQLO (3.8) > LEVI'S (3.4) > GIORDANO (2.6) > BUCKAROO (2.4) > GUESS (2.2) showed satisfactory fit levels $\langle T a b .13\rangle$. As in the evaluation of movements, the fit satisfaction level were high in areas like the waist and belly, with scores coming in at 3.5 or higher, although the knees, crotch, thighs, and hips were ranked as the areas were discomfort was felt, listed in the order of the discomfort level.

\section{2) Sensory evaluation of appearance}

In the sensory evaluation of appearance $<T a b$. 14>, with 13 questions regarding the front part, 4 questions on the side, and 11 questions on the back part <Tab. 3>, GIORDANO (4.2) > CK JEANS (3.8) > GUESS (3.7) > LEVI'S/BUCKAROO (3.6) > UNIQLO (3.4) were ranked as satisfactory in terms of fit. The sensory evaluation of appearance showed the following satisfaction levels (in descending order): sides (4.0) > front (3.9) > back (3.8). After averaging the scores for the different body parts, the front and back crotch areas, the hem circumference, and the inseam positions on the sides were pointed out as problems, with 3.5 points or lower. On the other hand, the front/back thigh areas and the waist area on the sides showed high levels of satisfaction in terms of fit <Fig. 3>. 
Journal of Fashion Business Vol.16, No.6

$\langle$ Tab. 12> Evaluation of movements results of body parts in movements

(Mean, $\mathrm{N}=3$ )

\begin{tabular}{|c|c|c|c|c|c|c|c|}
\hline Mov. & Brand & Waist & $\begin{array}{c}\text { Abdominal } \\
\text { Region }\end{array}$ & Hip & Thigh & Crotch & Knee \\
\hline \multirow{6}{*}{1} & GUESS & 3.3 & 3.0 & 2.3 & 3.0 & 2.3 & 2.7 \\
\hline & CK JEANS & 4.7 & 4.8 & 5.0 & 4.3 & 4.3 & 4.7 \\
\hline & BUCKAROO & 3.0 & 2.3 & 3.0 & 2.7 & 2.7 & 3.7 \\
\hline & LEVI'S & 4.3 & 3.7 & 4.0 & 4.7 & 4.0 & 3.7 \\
\hline & GIORDANO & 3.7 & 3.3 & 4.0 & 3.3 & 2.3 & 3.3 \\
\hline & UNIQLO & 4.7 & 4.7 & 5.0 & 4.0 & 4.0 & 4.3 \\
\hline \multirow{6}{*}{2} & GUESS & 2.3 & 2.7 & 2.3 & 2.7 & 2.3 & 2.7 \\
\hline & CK JEANS & 4.3 & 4.8 & 4.3 & 4.3 & 4.7 & 4.7 \\
\hline & BUCKAROO & 2.7 & 3.0 & 2.3 & 2.7 & 2.7 & 2.7 \\
\hline & \begin{tabular}{|l|} 
LEVII'S \\
\end{tabular} & 4.0 & 3.7 & 4.3 & 4.0 & 3.3 & 4.0 \\
\hline & GIORDANO & 3.0 & 4.0 & 3.0 & 3.3 & 3.0 & 3.3 \\
\hline & UNIQLO & 4.3 & 4.7 & 4.3 & 3.7 & 4.0 & 4.7 \\
\hline \multirow{6}{*}{3} & GUESS & 3.3 & 3.3 & 2.3 & 2.3 & 2.0 & 2.3 \\
\hline & CK JEANS & 4.7 & 4.7 & 4.7 & 4.0 & 3.3 & 3.3 \\
\hline & BUCKAROO & 3.0 & 2.7 & 2.0 & 2.0 & 2.0 & 1.7 \\
\hline & LEVII'S & 3.7 & 4.3 & 4.3 & 3.7 & 3.7 & 3.3 \\
\hline & GIORDANO & 2.7 & 3.3 & 3.7 & 3.0 & 3.7 & 2.7 \\
\hline & UNIQLO & 4.3 & 4.3 & 4.3 & 3.7 & 4.3 & 3.7 \\
\hline \multirow{6}{*}{4} & GUESS & 3.0 & 2.7 & 2.3 & 2.0 & 2.0 & 2.3 \\
\hline & CK JEANS & 4.7 & 4.8 & 4.3 & 4.3 & 3.0 & 3.7 \\
\hline & BUCKAROO & 2.7 & 2.7 & 2.3 & 1.7 & 2.3 & 2.0 \\
\hline & LEVII'S & 3.7 & 3.3 & 3.3 & 4.0 & 3.0 & 4.0 \\
\hline & GIORDANO & 3.0 & 2.7 & 2.7 & 2.3 & 3.0 & 2.7 \\
\hline & UNIQLO & 4.5 & 4.5 & 4.0 & 4.3 & 4.7 & 3.7 \\
\hline \multirow{6}{*}{5} & GUESS & 1.7 & 2.7 & 1.7 & 1.3 & 2.3 & 1.3 \\
\hline & CK JEANS & 4.8 & 4.8 & 3.0 & 3.3 & 3.7 & 3.0 \\
\hline & BUCKAROO & 2.0 & 2.7 & 2.0 & 2.0 & 2.0 & 1.3 \\
\hline & LEVII'S & 3.3 & 3.3 & 3.3 & 2.7 & 3.3 & 2.7 \\
\hline & GIORDANO & 2.7 & 2.0 & 2.3 & 1.3 & 2.0 & 1.3 \\
\hline & UNIQLO & 4.5 & 4.3 & 4.3 & 3.3 & 4.0 & 3.0 \\
\hline \multirow{7}{*}{6} & GUESS & 1.7 & 2.7 & 1.7 & 1.3 & 2.0 & 1.3 \\
\hline & CK JEANS & 4.7 & 4.7 & 4.0 & 3.3 & 4.3 & 3.0 \\
\hline & BUCKAROO & 2.3 & 2.0 & 2.7 & 2.0 & 2.3 & 1.3 \\
\hline & LEVII'S & 3.7 & 3.0 & 3.0 & 2.3 & 3.0 & 2.3 \\
\hline & GIORDANO & 1.3 & 2.3 & 1.7 & 1.0 & 1.7 & 1.3 \\
\hline & UNIQLO & 4.3 & 4.3 & 4.0 & 4.0 & 3.7 & 4.3 \\
\hline & Total & 3.5 & 3.5 & 3.2 & 3.0 & 3.1 & 2.9 \\
\hline
\end{tabular}


Lee Minjeong - Sohn Heesoon / Basic Research on the Development of Skinny Jean Pants for Korean Women in Their 20s

$\langle$ Tab. 13> Comprehensive total evaluation of movements of body parts

(Mean, $\mathrm{N}=3$ )

\begin{tabular}{l|c|c|c|c|c|c|c}
\hline $\begin{array}{l}\text { Part } \\
\text { Brand }\end{array}$ & Waist & $\begin{array}{c}\text { Abdomina } \\
\text { I Region }\end{array}$ & Hip & Thigh & Crotch & Knee & Total \\
\hline GUESS & 2.7 & 2.3 & 2.3 & 2.3 & 2.0 & 1.3 & 2.2 \\
\hline CK JEANS & 5.0 & 5.0 & 4.3 & 4.3 & 4.0 & 4.3 & 4.5 \\
\hline BUCKAROO & 3.3 & 3.0 & 2.3 & 2.3 & 2.0 & 1.7 & 2.4 \\
\hline LEVI'S & 4.0 & 4.0 & 3.7 & 3.0 & 3.3 & 2.3 & 3.4 \\
\hline GIORDANO & 3.0 & 3.3 & 2.7 & 3.0 & 1.7 & 1.7 & 2.6 \\
\hline UNIQLO & 4.3 & 4.0 & 3.6 & 4.0 & 3.3 & 3.7 & 3.8 \\
\hline \multicolumn{1}{r|}{ Total } & 3.7 & 3.6 & 3.2 & 3.2 & 2.7 & 2.5 & - \\
\hline \hline
\end{tabular}

$\langle$ Tab. 14> Sensory evaluation of appearance by brand

(Mean, $\mathrm{N}=6$ )

\begin{tabular}{l|c|c|c|c}
\hline \multirow{2}{*}{ Brand } & Part & Side & Back & Total \\
\hline GUESS & 4.0 & 4.3 & 4.0 & 3.7 \\
\hline CK JEANS & 4.5 & 4.2 & 4.3 & 3.8 \\
\hline BUCKAROO & 3.5 & 3.8 & 3.3 & 3.6 \\
\hline LEVI'S & 3.3 & 3.8 & 3.2 & 3.6 \\
\hline GIORDANO & 4.5 & 4.3 & 4.3 & 4.2 \\
\hline UNIQLO & 3.3 & 3.8 & 3.7 & 3.4 \\
\hline Total & 3.9 & 4.0 & 3.8 & - \\
\hline \hline
\end{tabular}

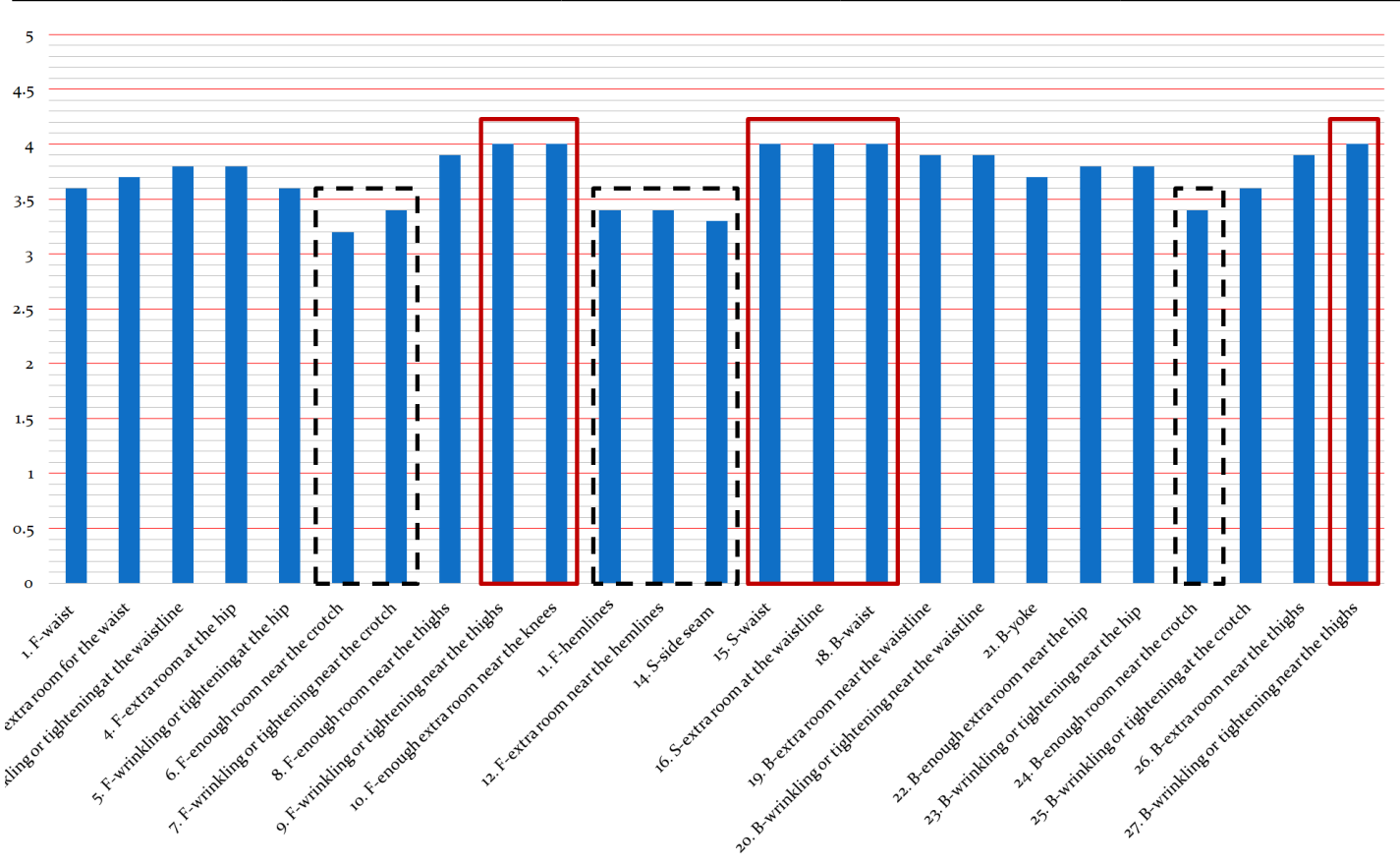

<Fig. 3> Comparison of the fit satisfaction levels of different brands and body parts 


\section{Conclusion}

The research showed that female jeans consumers in the early 20 s buy jeans that are priced moderately 50,000-99,000 won. In general, CK Jeans, Guess, and Levi's were strong in brand recognition and preference, in line with their jeans market shares. UNIQLO, in particular, showed a high level of brand recognition and popularity despite its being a low-end brand. This shows a high-level correlation between the female college students' shopping pattern and their average monthly income, and a high level of satisfaction when factoring in the competitive price factor. In terms of preferred styles, most of the subjects $(50.7 \%)$ preferred skinny jeans, and it was confirmed that it was the most hot trend at this point. The survey results show a general satisfaction with the fit, but the short crotch length in some of the recent models was pointed out as problematic.

The results of the satisfaction with the fit by brand showed that CK Jeans (4.5) and Uniqlo (3.8) were evaluated to be superb in the comprehensive total evaluation of movements while the body areas like the knees, thighs, crotch, and hips were pointed out as areas of discomfort when wearing skinny jeans. Giordano (4.2) and CK Jeans (3.8) were evaluated as satisfactory in the sensory evaluation of appearance. The hip, crotch, and the hemline areas were evaluated as uncomfortable in both the evaluation of movements and sensory evaluation of appearance. In conclusion, CK Jeans ranked as the superb brand for skinny jeans in terms of physical suitability, and the low-end UNIQLO was also ranked high in terms of preference and satisfaction with the fit. Meanwhile, research and development efforts are urgently need as both the evaluation of movements and sensory evaluation of appearance showed that the fit in the crotch and hip areas was not satisfactory.

The stylish fit of clothing depends on subjective, esthetic evaluation, and therefore, this study has limitations because of the many possible interpretations of fashion trends and the variety of consumer groups. This study also had limitations due to its timing and the fashion trend discrepancy in the textile ratio of different brands. Therefore, this study excluded such factors and evaluated only the subjects' satisfaction with the fit of the jeans. The study is meaningful in that it helps identify the skinny jeans brands that are most suitable for Korean women in their 20s. CK Jeans ranked no. 1 in terms of brand recognition and preference, and UNIQLO ranked high in stylish fit and in price competitiveness. It is believed that the fact that the greatest discomfort was reported in the crotch area needs to be considered in the further development of skinny jeans for Korean women in their $20 \mathrm{~s}$.

\section{Reference}

1) KOFOTI(2012), $2012 \mathrm{SS} \mathrm{KFI}$ research analysis \& 2012 FW Market Forecasting, pp.89-123.

2) Department of Fashion, "2012 SS research analysis of Jean Casual Market \& 2012 FW Market Forecasting", FASHION CHANNEL, 2012. 7, pp.24-133.

3) Lee Minjeong, Sohn Heesoon(2012. 10. 27), "Analysis of skinny jeans fit for women in their 20s by brand", Proceeding of The Korean Society of Fashion Business, pp.77-79.

4) "Skinny Jean Pants", Stylet magazine Retrieved 
Lee Minjeong - Sohn Heesoon / Basic Research on the Development of Skinny Jean Pants for

2012. 07. 02, from http://www.stylet.com

5) Kim Heeson, Kim Hyesoo \& Jeon Misun (2008), "The Study on Actual Condition and Comparison of Cognition on College Women's Wearing Blue Jeans by Change of Crotch Length of Hipbone Blue Jeans", The Research Journal of the Costume Culture, 16(6), pp.1087-1098.

6) Choi Jin, Do Wolhee(2008), "Transactions : A Study on the Actual Wearing Conditions and Fit Preferences of Boots-cut Jean -Focus on Adult Women in Their 20's and 30 's", Journal of the Korean Society of Clothing and Textiles, 32(2), pp.271-283.

7) Kim Younjoo et al.(2011. 11. 18), "Analysis of female college students' jeans wearing pattern", Proceeding of The Korea Fashion Costume Design Association, pp.62-66.

8) Kim Hyuna, Chun Jongsuk(2011), "A Comparative Study on the Fit of Jean Block Patterns for Women in their 20s", Journal of the Korean Society of Clothing and Textiles, 35(2), pp.136-145.

9) Yoon Jinah(2007), "Female College Students' Jean Pants Style : With a Focus on Skinny Jean", Journal of the Korean Fashion \& Costume Design Association, 9(1), pp.189201.

10) Kim Kyunghee, Lee Kunhee(2009), "A study on the blue jeans design according to on lower body type : A focus of the body types of a woman in her twenties", Journal of Korean Traditional Costume, 12(3), pp. 103-113.

11) Un Mikyung, Suh Mia(2007), "The Development of Jeans Pattern for Stretch Denim Fabrics", Journal of the Korea Fashion \& Costume Design Association, 9(3), pp.191-203.
12) Uh Mikyung, Kim Kyunga \& Suh Mia(2008), "The Development of Jeans Pattern for Non-Stretch Denim Fabrics : The Comparison of Bio, Bio Stone, Bio Stone Bleach Washing Finishing", The Research Journal of the Costume Culture, 16(3), pp.461-474.

13) Suh Chuyeon, Suk Eunyoung \& Park Soonjee(2005), "Comparative Study of Ready-to-made Denim Pants According to Pattern Analysis and Appearance Evaluation", Korean Journal of Human Ecology, 7(3), pp.5-13.

14) Park Nari, Park Jeaok(2009), "Purchasing Behavior and Evaluate Criteria of Jeans Consumers", Journal of Korean Traditional Costume, 17(4), pp. 548-560.

15) Park Sookyeong, Lim Sookja(2011), "A Study on the Consumer Satisfaction of Expectance, Performance, Post-purchase Behavior toward Jeans Wear between Korea and The United States", Journal of Korean Traditional Costume, 19(2), pp.269-282.

16) Kim Younjoo et al., pp.62-66.

17) Lee Minjeong, Sohn Heesoon, op.cit., pp.77 -79 .

18) Kang Yeonkyung et al.(2011), "Analysis on Lower Body Type of Korean Women in Their Early 20's", Journal of Fashion Business, 16(6), pp.148-162.

19) Retrieved 2011. 5. 10 from http://sizekorea. kats.go.kr

접수일(2012년 12월 27일), 수정일(1차 : 2012년 12월 11일), 게재확정일(2012년 12월 17일) 